\title{
Stress-induced analgesia: Adaptation following chronic cold water swims
}

\author{
RICHARD J. BODNAR, DENNIS D. KELLY, ANGELA SPIAGGIA, \\ and MURRAY GLUSMAN \\ Department of Behavioral Physiology, New York State Psychiatric Institute \\ and Department of Psychiatry, Columbia University, New York, New York 10032
}

\begin{abstract}
Rats exposed to novel stressful events subsequently display increased nociceptive thresholds for up to $2 \mathrm{~h}$. The present study investigated whether the analgesia induced by one such stressor, a brief, forced, cold water swim would show adaptation with repeated exposures in the same manner that other stress-induced physiological responses adapt. Acutely exposed rats displayed profound postswim elevations in flinch-jump thresholds, but rats that were chronically exposed to 14 daily cold water swims displayed thresholds similar to unstressed rats when tested $30 \mathrm{~min}$ after the final swim condition, indicating adaptation of pain thresholds to continued stress. Moreover, peripheral and core hypothermia could not account for analgesic effectiveness, since both the nonanalgesic chronic and analgesic acute groups displayed significantly lower rectal and skin temperatures throughout the testing period.
\end{abstract}

When first exposed to a stressful event, rats display a transient yet significant increase in nociceptive thresholds. Following the initial observation (Hayes, Bennett, Newlon, \& Mayer, 1976) that rats showed increased tail-flick latencies following acute exposure to such severe stresses as inescapable footshock, rotation or intraperitoneal injections of hypertonic saline (Hayes et al., 1976), a number of other effective stressors have been identified, such as cold water swims (Bodnar, Kelly, \& Glusman, 1978; Bodnar, Kelly, Spiaggia, \& Glusman, 1977), food deprivation (Spiaggia, Bodnar, Kelly, McManus, \& Glusman, 1977), and administration of 2-deoxy-D-glucose, which produces glucoprivation (Bodnar, Brutus, Glusman, \& Kelly, Note 1). To date, the only apparent experimental stressor that has not induced a measurable period of analgesia is the inhalation of ether vapors (Hayes, et al., 1976). Since hormonal responses to stress vary according to the nature of the stressor (Mason, 1968a, 1968b), it should not be unexpected that the analgesic response to stress might similarly vary across stressors. Thus, while ether does produce a classic cortisol response, it does not similarly affect the sympathomedullary system (Makara, Stark, \& Palkovits, 1970; Makara, Stark, Palkovits, Revesz, \& Mihaly, 1969; Stark, Acs, Makara, \& Mihaly, 1968), nor does it represent the type of environmental stimulus for which this pain-modulating system may have evolved.

R.J. Bodnar was supported by postdoctoral National Institute of Mental Health Grant 13579. The research was supported by New York State Health Research Council Grants 922 to R. J. Bodnar and 365 to D. D. Kelly. We thank L. Skaredoff and M. Favetta for technical assistance. Requests for reprints should be sent to R. J. Bodnar, Department of Behavioral Physiology, New York State Psychiatric Institute, 722 West 168 Street, New York, New York 10032.
Given the number and range of novel environmental events that increase nociceptive thresholds, it would seem unlikely that various nonspecific peripheral factors peculiar to the individual stressors could account for the threshold elevations. Rather, it would seem that a temporary reduction in sensitivity to painful stimuli may be one of a shifting collection of physiological responses to challenging environmental stimuli that collectively define a stress response. If so, one would expect that the poststress analgesic response would adapt following repeated exposure to the particular stressor. Selye (1952) demonstrated that the automatic and neuroendocrine responses observed following acute exposure to stress were markedly attenuated following chronic exposure. Recent observations indicate that the nociceptive elevations following stress may also adapt. Increases in tail-flick latencies following acute exposure to inescapable footshock were eliminated following chronic exposure (Akil, Madden, Patrick, \& Barchas, 1976, pp. 63-70; Madden, Akil, Patrick, \& Barchas, 1977).

The present study examined whether repeated exposure to another analgesically effective stressor (Bodnar et al., 1977), a brief, forced, cold water swim, would result in adaptation of the analgesic response, but not its peripheral nonspecific effects. Concomitant core body and skin termperatures were also monitored to determine whether hypothermia could reliably predict nociceptive threshold alterations.

\section{METHOD}

\section{Flinch-Jump Testing}

Eighteen male albino Holtzman Sprague-Dawley rats $(350-500 \mathrm{~g})$ were tested for flinch-jump thresholds using a modification of the Evans (1961) procedure. Testing was carried out in a Plexiglas chamber that had a $30 \times 24 \mathrm{~cm}$ grid floor 
composed of 14 bars $(.6 \mathrm{~cm}$ in diameter) spaced $1.8 \mathrm{~cm}$ apart. Electric shocks were delivered through the grids by a $60-\mathrm{Hz}$ constant-current shock generator through a 14-pole shock scrambler. Using an ascending method of limits of successively more intense shock, the flinch threshold was defined in milliamperes as the lowest intensity that elicited a withdrawal of a single paw from the grids. The initial jump threshold was defined as the lowest intensity that elicited simultaneous withdrawal of both hindpaws from the grids. The jump threshold was defined as the lowest of two consecutive intensities that elicited a jump as above. Each trial began with the animal receiving a $200-\mathrm{msec}$ footshock at a current intensity of .1 mA. Subsequent shocks were increased in equal .05-mA steps at 20 -sec intervals. Following the determination of flinch, initial jump, and jump thresholds on each trial, the current intensity was reset to $.1 \mathrm{~mA}$ for the next trial until 10 trials were completed.

The 18 rats were randomly assigned to three groups of six subjects each. The first, or unstressed control, group underwent daily flinch-jump testing for 5 consecutive days. The second, or acute stress, group was exposed to the cold water stress condition $30 \mathrm{~min}$ prior to the first of 5 days of flinch-jump testing. The third, or chronic stress, group was exposed to the stress condition daily for 14 days and then tested behaviorally $30 \mathrm{~min}$ following the last stress session for 4 additional nonstress days as with the preceding groups.

In the cold water stress condition, each animal was placed in a bath of $2^{\circ} \mathrm{C}$ ice water and forced to swim for $3.5 \mathrm{~min}$. The water was too deep for the animal to stand without being submerged. Between swim exposure and psychophysical testing, the rats were placed in individual cages lined with newspaper.

\section{Core and Skin Temperature Determinations}

A fourth group of six additional naive male rats was immersed in cold water $3.5 \mathrm{~min}$ daily for 14 days. Three weeks later, each animal was subjected to a warm water control condition, which was identical to the cold water stress condition except the water temperature was $28^{\circ} \mathrm{C}$. Core body temperatures and skin temperatures were recorded on the first and last days of the cold water stress sequence and on the warm water control day. On each test day, the core and skin temperatures for each animal were determined at nine different times: 15 min preswim, immediately preceding immersion, and postswim at $0,15,30$, $60,120,180$, and $240 \mathrm{~min}$. Core body temperatures were measured with the rectal probe of a Bailey digital thermometer (BAT-8); skin temperatures were determined by applying the probe to the plantar surface of the left hindpaw.

\section{RESULTS}

Figure 1 shows that, whereas acute exposure to a cold water swim elevated all three nociceptive measures, chronic cold water swims did not. Post hoc Tukey comparisons revealed that both jump and initial jump thresholds of acutely stressed rats were significantly elevated following the cold water swim, as compared to baseline sessions [jump, $\mathrm{t}(5)=5.15, \mathrm{p}<.01$; initial jump, $\mathrm{t}(5)=4.10, \mathrm{p}<.01]$. In contrast, both jump and initial jump thresholds of chronically stressed rats were unaltered as compared to baseline [jump, $\mathrm{t}(5)=.96$; initial jump, $\mathrm{t}(5)=.45$ ] and to unstressed control values [jump, $t(5)=2.04$; initial jump, $t(5)=2.19]$. Flinch thresholds displayed a similar pattern. Baseline values for each nociceptive measure did not differ among the three groups.

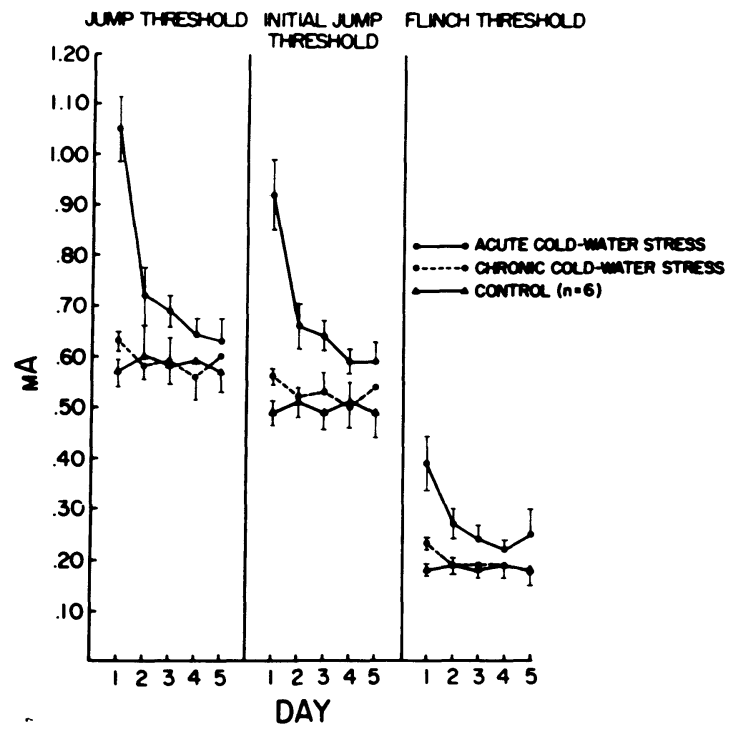

Figure 1. Alterations in flinch-jump thresholds for 5 days following either acute exposure to cold water stress or the last of 14 (chronic) exposures to the cold water stress. The test on Day 1 occurred $30 \mathrm{~min}$ following the swim.

As seen in Figure 2, core body temperatures were significantly reduced after the cold water swims in both the acute and chronic groups, but not after the warm water control condition. Core temperatures in the acute cold water stress condition were significantly reduced for $60 \mathrm{~min}$ after immersion with a maximal reduction of $10^{\circ} \mathrm{C}$ at $15 \mathrm{~min}$ and a return to normal by $120 \mathrm{~min}$. A similar, if milder, pattern of core temperature changes occurred in the chronic cold water stress condition, with a maximal reduction of $6^{\circ} \mathrm{C}$ at $15 \mathrm{~min}$ and a return to normal by $60 \mathrm{~min}$. At $30 \mathrm{~min}$ postswim, core temperature reductions were significantly greater in the acute cold water stress condition than in either the chronic cold water condition $[\mathrm{t}(5)=10.28, \mathrm{p}<.01]$ or the warm water control condition $[t(5)=22.45, p<.01]$. In turn, the core temperatures of the chronically stressed rats were significantly lower than when placed in warm water $[\mathrm{t}(5)=15.51, \mathrm{p}<.011$.

While only cold water stressed rats showed significant core temperature reductions, skin temperatures showed significant reductions in all three conditions [ANOVA, $F(2,135)=152.68, p<.01]$. The acute cold water stress condition elicited a maximal skin temperature reduction immediately after the swim of $16^{\circ} \mathrm{C}$, representing a $50 \%$ fall from normal skin temperature; skin temperatures returned to normal by $180 \mathrm{~min}$. Similarly, the chronic cold water stress condition elicited a maximal skin temperature reduction of $15^{\circ} \mathrm{C}$ immediately after immersion and return to normal by $1 \mathrm{~h}$. While skin temperatures in the warm water control condition were reduced for up to $60 \mathrm{~min}$ after immersion, the maximal skin temperature reduction at 


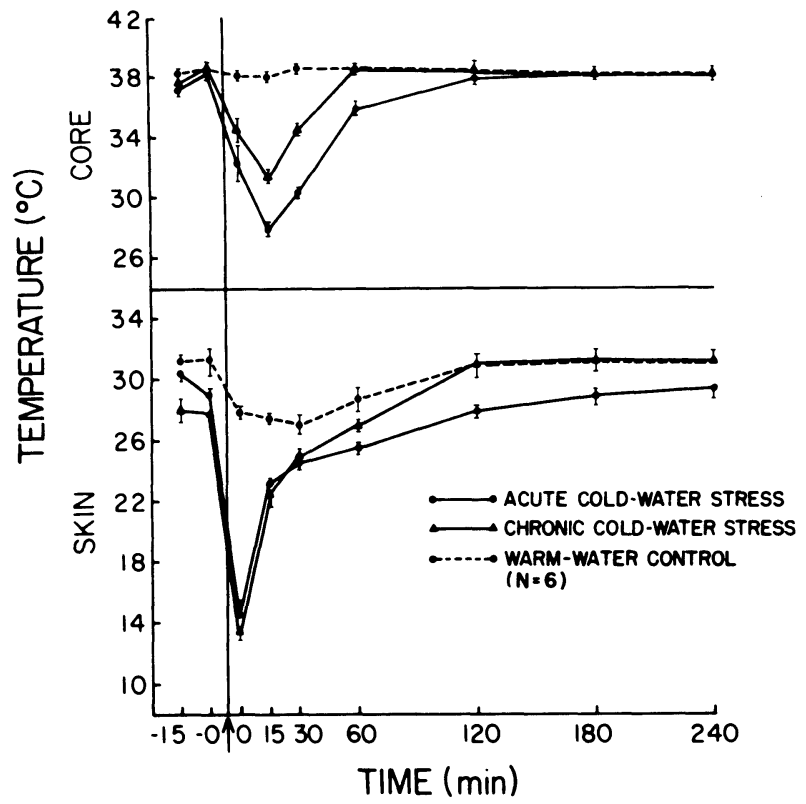

Figure 2. Time course of alterations in core body and skin temperatures following acute exposure to the cold water stress, the last of 14 cold water swims (chronic stress), or a single warm water control swim.

$30 \mathrm{~min}$ was only $5^{\circ} \mathrm{C}$. Thus, at $30 \mathrm{~min}$ postswim, the skin temperatures of both the acute and chronic cold water stressed rats were both significantly lower than the warm water controls [acute vs. warm, $t(5)=3.41$, $\mathrm{p}<.02$; chronic vs. warm, $\mathrm{t}(5)=3.04, \mathrm{p}<.05$ ], whereas the differences between the acute and chronic cold water stressed animals did not reach statistical significance $[t(5)=.054]$.

\section{DISCUSSION}

These data show that the acute stress of a single, forced, cold water swim resulted in elevated flinch-jump thresholds, confirming prior observations for this and other stressors (Akil et al., 1976; Bodnar et al., 1977, 1978, Note 1; Hayes et al., 1976; Madden et al., 1977). However, repeated exposure to the same stressor over a period of 14 days eliminated or significantly attenuated the analgesic effects of the cold water swim. Except for partially elevated flinch thresholds, chronically stressed rats resembled unstressed controls in their responses to shock, in spite of their immersion in $2^{\circ} \mathrm{C}$ water just $30 \mathrm{~min}$ before threshold testing. The adaptation of cold water swim induced analgesia to repeated exposure in the present experiment supports other observations that repeated daily exposures to electric footshock resulted in an attenuation of tail-flick latency alterations (Akil et al., 1976; Madden et al., 1977). Adaptation of a similar nature may be involved in findings of Weiss and his co-workers that acquisition of an active avoidance response is retarded in rats exposed to a single stressful episode, whereas the learning of chronically stressed animals is not (Glazer, Weiss, Pohorecky, \& Miller, 1975; Weiss \& Glazer, 1975; Weiss, Glazer, Pohorecky, Brick, \& Miller, 1975).

It is also clear from these results that hypothermia cannot account for increased nociceptive thresholds after stress. First, repeated exposure to cold water stress still resulted in significant core hypothermia for up to $30 \mathrm{~min}$ following the swims despite adaptation of flinch-jump thresholds. Second, both acute and repeated exposures to cold water stress produced equivalent reductions in skin temperature for up to $30 \mathrm{~min}$ following the swim. Only acute cold water stress produced profound analgesia; repeated cold water stress did not. Third, reductions in skin temperatures in acutely stressed animals outlasted the duration of stress-produced analgesia. These observations closely parallel those of Weiss, Glazer, \& Pohorecky (1976) involving brain temperature. In their experiments, repeated cold water swims still resulted in brain hypothermia, however, active avoidance deficits were markedly attenuated.

Although the acute and chronic groups both showed significant reductions in core body temperature following the cold water swim, the fall in core body temperature was somewhat attenuated in the chronically stressed animals. Evidently, following repeated immersion in ice water, chronically stressed animals showed slightly better core body thermoregulation. Thus, while it appears unlikely that lowered body temperatures account for acute swim-induced analgesia, these data leave open the possibility that there may exist a critical level of hypothermia somewhere in the $3^{\circ}$ range between the significantly reduced temperature levels of the acute and chronic animals, which might trigger an analgesic response in the former but not the latter.

Exposure to stressful situations has long been known to induce a profile of physiological adaptations, or stress reactions. The present and other recent data suggest that a temporary decline in sensitivity to pain may also be one of the body's normal responses to stress. Thus, in addition to well documented central neural changes in sympathetic arousal and pituitaryadrenal activation, another coping response cued by the nervous system may be the activation of a pain-modulating system that dampens normal reactions to pain during periods of stress.

\section{REFERENCE NOTE}

1. Bodnar, R. J., Brutus, M., Glusman, M., \& Kelly, D. D. Analgesia induced by 2-deoxy-D-glucose, an antimetabolic glucose analogue. Manuscript submitted for publication, 1978.

\section{REFERENCES}

Akil, H., Madden, J., Patrick, R. L., \& Barchas, J. D. Stress-induced increase in endogenous opiate peptides: Concurrent analgesia and its partial reversal by naloxone. In H. W. Kosterlitz (Ed.), Opiates and endogenous opioid peptides. Amsterdam: North Holland, 1976.

Bodnar, R. J., Kelly, D. D., \& Glusman, M. Stressinduced analgesia: Time course of pain reflex alterations following cold water swims. Bulletin of the Psychonomic Society, 1978, $11,333-336$.

Bodnar, R. J., Kelly, D. D., Spiaggia, A., \& Glusman, M. Analgesia produced by cold-water stress: Effect of naloxone. Federation Proceedings, 1977, 36.

Evans, W. O. A new technique for the investigation of some analgesic drugs on a reflexive behavior in the rat. Psychopharmacology, 1961, 2, 318-325.

Glazer, H. I., Weiss, J. M., Pohorecky, L. A., \& Miller, N. E. Monoamines as mediators of avoidance-escape behavior. Psychosomatic Medicine, 1975, 37, 535-543.

Hayes, R. L., Bennett, G. J., Newlon, P., \& Mayer, D. J. Analgesic effects of certain noxious and stressful manipulations in the rat. Society Neuroscience Abstracts, 1976, 2, 1350.

Madden, J., Akil, H., Patrick, R. L., \& Barchas, J. D. Stress-induced parallel changes in central opioid levels and pain responsiveness in the rat. Nature, 1977, 265, 358-360.

Makara, G. B., Stark, E., \& Palkovits, M. Afferent pathways of stressful stimuli: Corticotropin release after hypothalamic deafferentation. Journal of Endocrinology, 1970, 47, 411-416. 
Makara, G. B., Stark, E., Palkovits, M., Revesz, T., \& Mihaly, K. Afferent pathways of stressful stimuli: Corticotropin release after partial deafferentation of the medial basal hypothalamus. Journal of Endocrinology, 1969, 44, 187-193.

Mason, J. W. A review of psychoendocrine research on the pituitary-adrenal cortical system. Psychosomatic Medicine, 1968, 30, 576-607. (a)

MAson, J. W. A review of psychoendocrine research on the sympathetic adrenal medullary system. Psychosomatic Medicine, 1968, 30, 631-653. (b)

SELYE, H. The story of the adaptation syndrome. Montreal: Acta, 1952.

Spiaggia, A., Bodnar, R. J., Kelly, D. D., McManus, M. E., \& GlusmaN, M. Biphasic alterations in nociceptive thresholds after food deprivation. Society Neuroscience Abstracts, 1977, 3, 492.

Stark, E., Acs, Z., Makara, G. B., \& Mihaly, K. The hypophyseal-adrenocortical response to various different stressing procedures in ACTH treated rats. Canadian Journal of Physiology, 1968, 46, 567-571.

Weiss, J. M., \& Glazer, H. I. Effects of acute exposure to stressors on subsequent avoidance-escape behavior. Psychosomatic Medicine, 1975, 37, 499-521.

Weiss, J. M., Glazer, H. I., \& Pohorecky, L. A. Coping behavior and neurochemical changes: An alternative explanation for the original "learned helplessness" experiments. In G. Serban \& A. Kling (Eds.), Animal models in human psychobiology. New York: Plenum Press, 1976.

Weiss, J. M., Glazer, H. I., Pohorecky, L. A., Brick, J., \& Miller, N. E. Effects of chronic exposure to stressors on avoidance-escape behavior and on brain norepinephrine. Psychosomatic Medicine, 1975, 37, 522-534.

(Received for publication January 20, 1978.) 